DOCTRINA

\title{
La entrevista videograbada de la Ley 21.057: Un instrumento que reivindica el interés superior de niños, niñas y adolescentes y su naturaleza jurídica como sujetos de derechos en Chile
}

\author{
The video-recorded interview of Law 21,057: An instrument that claims \\ the best interests of the child and their juridical nature as subjects of rights in Chile
}

\author{
Sergio Andrés Henríquez Galindo (iD) \\ Universidad de Chile
}

\begin{abstract}
RESUMEN Este artículo expone el cambio de paradigma que significó la aprobación de la Ley 21.057, que pasa de considerar a los niños, niñas y adolescentes como meros objetos de pericia y de protección, a ser considerados sujetos de derechos, mediante un sistema de entrevistas videograbadas y entrevistadores calificados que asisten a jueces, fiscales y otros actores del sistema judicial, con el objeto de brindar una justicia eficaz y humana que reconoce su dignidad. Se examinan así los principales argumentos en contra de este sistema, sus características y los desafíos que encuentra, entre otros, su implementación en medio de la pandemia de covid-19.
\end{abstract}

PALABRAS CLAVE Entrevistador, consejero técnico, derecho procesal penal, derecho procesal de familia, entrevista videograbada.

ABSTRACT This article exposes the paradigm shift that the approval of Law 21,057 signified, which goes from considering children and adolescents as mere objects of expertise and protection, to being considered subjects of rights, through a system of video-recorded interviews and Qualified interviewers, who assist judges, prosecutors and other actors in the judicial system, in order to provide effective and humane justice that recognizes their dignity. The main arguments against this system, its main characteristics and the challenges it encounters, among others, its implementation in the midst of the Covid-19 pandemic are thus examined.

KEYWORDS Interviewer, technical adviser, criminal procedure law, family procedural law, video recorded interview. 


\section{Introducción}

Para una mejor lectura del presente trabajo, se ha estructurado de la siguiente forma: i) una introducción al tema en estudio; ii) una primera sección que se dedicará a analizar las objeciones que se han planteado respecto de la entrevista videograbada; iii) una segunda sección que realiza una exposición dogmática y crítica de los principales elementos de la Ley 21.057; iv) una tercera sección que expondrá la situación actual de la entrevista videograbada y sus perspectivas de futuro; $y \mathrm{v}$ ) conclusiones.

Sirva el presente apartado introductorio, además, para señalar el valor que para el debido proceso representa un juicio acusatorio que garantice la igualdad de armas y el derecho a la defensa, es inestimable y fundamental para una sociedad democrática de derecho, y en nuestro actual proceso penal, fiscal acusador, defensor y juez imparcial forman la tríada del proceso para materializar este derecho. Por otro lado, la víctima, como sujeto procesal, ha pasado de ser mero espectador y objeto de pericias, a ser considerada como un sujeto de derechos. Así, para Duce (2014: 241), la víctima «llegó para quedarse», y su correcto abordaje es inevitable e imprescindible:

Me parece que más allá de la cuestión histórica acerca de la evolución del rol de la víctima, creo que el punto central a considerar hoy día y que debiera orientar los debates es que la víctima ha «llegado para quedarse» en nuestros sistemas procesales o, dicho de otra manera, ha pasado de ser «un actor de reparto a uno de los protagonistas» de la trama procesal. Más allá de los debates acerca del alcance de los derechos que debieran o no reconocerse a las víctimas, a esta altura del partido las posturas que perpetúan la expulsión del ofendido del proceso penal no son defendibles.

Dicho esto, podemos decir que, tratándose de adultos, en general esto se cumple, aunque no llegan a tener un protagonismo equivalente a los demás sujetos procesales, sin perjuicio de que siempre cualquier sistema procesal penal es perfectible. ${ }^{1}$ Pero los seres humanos somos distintos. Algunos se encuentran en proceso de desarrollo sicosomático y social, como los niños, niñas y adolescentes, quienes son distintos a los adultos, pero ello no los hace menos dignos.

Los adultos han diseñado un sistema procesal penal para adultos. Pueden elegir

1. Ya en 2007 se anunciaba la creación de un Servicio Nacional de Apoyo a las Víctimas: «Ministro Peñailillo: "Este año presentaremos un proyecto de ley para la creación del Servicio Nacional de Apoyo a Víctimas"», Ministerio del Interior y Seguridad Pública de Chile, 7 de abril de 2015, disponible en bit. ly/3qjhh92. Mismo hecho que se ha repetido recientemente con un nuevo anuncio del mismo servicio: Boletín 12.991-07, Cámara de Diputados, Crea el Servicio Nacional de Acceso a la Justicia y la Defensoría de Víctimas de Delitos, 5 de enero de 2021. Aunque es debatible en la doctrina si este nuevo servicio significa un avance o no para la protección de las víctimas y sus derechos: véase Cristian Riego, «Una mala idea», La Tercera, 8 de enero de 2021, disponible en bit.ly/3qpEHcX; y María Elena Santibáñez, «Un avance en acceso a la justicia», La Tercera, 8 de enero de 2021, disponible en bit.ly/2TYTn6V. 
a las autoridades legislativas y administrativas que implementaron el proceso penal, pero los niños no. Es relevante tener presente que Chile está comprometido con los niños y niñas hace ya más de 30 años, cuando en 1990 se ratificó y entró en vigor en Chile la Convención sobre Derechos del Niño de Naciones Unidas, que dejó atrás la doctrina del menor en situación irregular que se lo trata como objeto de protección, y en cambio lo eleva a la categoría de sujeto de derechos (véase García Méndez, 2004: 11). Ese compromiso implica adecuar el procedimiento a ellos y ellas, para que también se integren y sean reconocidos como tales, lo que implica dejar de mirar como lo hacen los adultos, para pasar a pensar como niños. El transcurso del tiempo es distinto para los niños, así como también es distinto su lenguaje, comunicación, forma de expresarse y de sentir, pero eso no los hace menos valiosos y dignos de consideración, como lo ha constatado empíricamente Cortés (2009: 25) al señalar que:

Se advierte que los niños, niñas y adolescentes entrevistados no perciben en buena parte del proceso judicial una atención dedicada, atenta, que se ponga en la difícil situación por ellos vivida. Excepción de esta valoración, la reciben profesionales especializados con entrenamiento para tratar este tipo de casos, como son las carabineras de la 48. ${ }^{a}$ Comisaría o los sicólogos de la [Unidad Regional de Atención a las Víctimas y Testigos]. La ausencia de este tipo de profesionales en el resto del proceso pone de manifiesto lo mucho que hay que trabajar para lograr que el trato dado a las víctimas y las características del proceso judicial no contribuya a profundizar el fenómeno revictimizado.

Existe un cuerpo normativo de derechos humanos que nos permite concluir que, a partir de su ratificación en Chile, los niños, niñas y adolescentes son sujetos de derechos y no meros objetos de protección. Entre otros, la Convención sobre Derechos del Niño (CDN), sus protocolos facultativos y, en particular, las Observaciones Generales 10, 12 y 14 del Comité de Derechos del Niño así lo establecen, cuando intervienen en procedimientos judiciales o administrativos que les afectan. El interés superior del niño, en su dimensión procedimental, consiste en que

siempre que se tenga que tomar una decisión que afecte a un niño en concreto, a un grupo de niños concreto o a los niños en general, el proceso de adopción de decisiones deberá incluir una estimación de las posibles repercusiones (positivas o negativas) de la decisión en el niño o los niños interesados. La evaluación y determinación del interés superior del niño requieren garantías procesales (Observación General 14, artículo 3, párrafo 1).

Sobre la forma en que se adoptan estas decisiones, la Observación General 12 establece cinco medidas que se deben adoptar para su efectivo cumplimiento: i) preparación, consistente en proporcionar información al niño, niña o adolescente, explicándole las consecuencias de sus decisiones; ii) audiencia, por la que se debe procurar 
que se efectúe en un contexto adecuado que proporcione confianza y seguridad; iii) evaluación de la capacidad del niño, que debe considerar su capacidad para formarse un juicio propio, caso en el cual quien adopte decisiones deberá tener en especial consideración su opinión; iv) información sobre la consideración otorgada a las opiniones del niño (comunicación de los resultados al niño); y v) quejas, vías de recurso y desagravio, por lo que debe la legislación considerar recursos cuando su derecho a ser escuchado sea violado. Al ser un sujeto de derechos, además debemos tener presente que tiene derecho a su integridad sicológica, garantizado por la Constitución y la $\mathrm{CDN},{ }^{2}$ entre otros instrumentos de derechos humanos, y que tal derecho no es disponible con el objeto de mejorar la persecución criminal o la conveniencia de las partes. Entonces, bajo este prisma, que considera a los niños y niñas víctimas de delitos sexuales y violentos como sujetos de derechos, y amparados en el derecho fundamental a la integridad sicológica, se está implementando la Ley 21.057, que configura una nueva forma de investigar y de conducir un procedimiento penal.

\section{Análisis crítico de las objeciones que se han planteado respecto de la entrevista videograbada}

A poco andar del anuncio del ingreso del proyecto de ley que establece un sistema de entrevistas videograbadas para los niños y niñas víctimas de delitos sexuales por parte del ministro del Interior de la época, Andrés Chadwick, ${ }^{3}$ diversas voces de especialistas se oponían a esta medida, aduciendo una posible vulneración al derecho a la defensa de los imputados o, por el contrario, un posible obstáculo en las investigaciones de dichos delitos que afectaría a las víctimas. Así, entre los argumentos contrarios a la entrevista videograbada, podemos esbozar los siguientes: ${ }^{4}$ «Es necesario que la víctima se someta al contrainterrogatorio del defensor», «la víctima debe declarar en el juicio oral», «se trata de una medida que afecta al derecho a la defensa», «disminuir el número de entrevistas dificultará la investigación, haciendo más difícil la obtención de pruebas para condenar», y «es extraño que el fiscal no pueda entrevistar a la víctima». En lo que sigue, se expondrán las razones por las cuales se estima que estas objeciones no son fundadas.

2. Artículo 19 número 1 de la Constitución Política de la República y artículos 19, 24 y 27 de la Convención sobre Derechos del Niño.

3. «Gobierno envía proyecto de ley de entrevistas videograbadas que busca proteger a menores víctimas de delitos sexuales», Ministerio del Interior y Seguridad Pública de Chile, 22 de enero de 2014, disponible en bit.ly/3d5PQKs.

4. Historia de la ley 21.057. Puede examinarse la historia de la ley para recoger estas y otras críticas iniciales, por ejemplo la sostenida por el fiscal nacional y el defensor nacional en su presentación ante la Comisión de Constitución, Legislación, Justicia y Reglamento del Senado, del 21 de diciembre de 2016, segundo informe, sesión 8o, legislatura 364, entre otras. 


\section{«La víctima debe someterse al contrainterrogatorio de la defensa»}

Así, cuando se afirma que «la víctima debe someterse al contrainterrogatorio de la defensa», hay que tener en cuenta que esta afirmación es correcta tratándose de niños, niñas y adultos. Por tanto, los niños y niñas víctimas de delitos sexuales deben someterse a esta herramienta básica de la defensa, a fin de garantizar la contradictoriedad que exige el derecho al debido proceso. Pero como los niños y niñas son distintos a los adultos, cabe preguntarse, entonces, si la forma de hacer este contrainterrogatorio puede ser la misma. La evidencia empírica y científica es contundente: no puede ser de la misma forma.

La investigación sicológica, que examina las capacidades de los niños como testigos, ha experimentado una revolución en los últimos 25 años. Los investigadores se inspiraron, originalmente, en la amplia cobertura de los medios de comunicación en las décadas de 1980 y 1990, de una serie de casos judiciales penales en los que niños en edad preescolar acusaron a los proveedores de guarderías y maestros de actos extraños de abuso sexual. El examen de las entrevistas de investigación en estos casos generalmente reveló un cuestionamiento muy sugerente. Los investigadores imitaron las técnicas coercitivas con niños en edad preescolar y demostraron altas tasas de respuestas falsas y, en los casos extremos, la formación de recuerdos falsos (Lyon, 2014: 73; la traducción es nuestra).

Esta necesidad de abordar el contrainterrogatorio de forma diferenciada se explica por el hecho de que los niños y niñas son distintos, tienen competencias y características diferentes y, por lo demás, tienen una protección adicional a sus derechos dada por su interés superior, que opera como una garantía de efectivo goce y respeto de sus derechos, como el derecho a la integridad sicológica. La forma de hacer el interrogatorio o contrainterrogatorio de los niños, niñas y adolescentes debe ser distinta, como se puede inferir de lo expresado por el Comité de Derechos del Niño de Naciones Unidas:

El interés superior del niño debe ser una consideración primordial en la adopción de todas las medidas de aplicación. La expresión «a que se atenderá» impone una sólida obligación jurídica a los Estados y significa que no pueden decidir a su discreción si el interés superior del niño es una consideración primordial que ha de valorarse y a la que debe atribuirse la importancia adecuada en cualquier medida que se tome $[. .$.$] Los Estados deben crear un entorno que respete la dignidad humana y$ asegure el desarrollo holístico de todos los niños. Al evaluar y determinar el interés superior del niño, el Estado debe garantizar el pleno respeto de su derecho intrínseco a la vida, la supervivencia y el desarrollo (Comité de Derechos del Niño de Naciones Unidas, 2013, párrafos 36 y 42).

¿Cuál es el objeto de un contrainterrogatorio? Servir de herramienta para «de- 
velar los defectos de la información de la prueba presentada», «desacreditar al testigo», «desacreditar el testimonio», «acreditar las proposiciones fácticas de la defensa», «acreditar prueba material propia» $\mathrm{y}$ «obtener inconsistencias en la prueba de la contraparte» (Baytelman y Duce, 2004: 60), a través del cuestionamiento de, al menos, dos niveles de la declaración tratándose de la víctima, consistentes en su credibilidad, y del real alcance de sus dichos.

Si bien el debido proceso exige poder contrainterrogar, también los derechos del niño exigen tener en consideración su interés superior, por lo que resulta necesario efectuar el contrainterrogatorio de una forma distinta para respetar ambas exigencias. Es posible cumplir con tales objetivos, respetando el derecho a la integridad sicológica de los niños, niñas y adolescentes víctimas de delitos sexuales y violentos, si se permite que se planteen preguntas usando un filtro que impida la afectación de su integridad sicológica. Si bien esto no está exento de dificultades, es valioso implementarlo, como postula Paul Reinhardt, quien describe la experiencia canadiense, al expresar que:

Me he convertido en un defensor del uso de las medidas de protección y asistencia testimonial para niños, porque permite que el niño testifique en un entorno más humano, sin socavar la habilidad del juez o del jurado para inspeccionar cuidadosamente su testimonio, con la ayuda de un contrainterrogatorio por parte del abogado defensor y la oportunidad de que el abogado presente pruebas de refutación para generar una duda razonable. Considero esencial que los tribunales implementen, junto con las nuevas tecnologías, programas educativos y de contención emocional para asistir al niño testigo [...] También estoy convencido de que existe una ventaja potencial cuando los fiscales pueden trabajar conjuntamente en un enfoque «de equipo» y convertirse en especialistas en esta compleja área de la ley. Además, estimo que todos los participantes del tribunal necesitan capacitación y educación acerca del uso de la asistencia testimonial y de los requisitos de las CFC (Reinhardt, 2009: 103).

Ese filtro puede ser un entrevistador entrenado y especializado en niños y niñas víctimas de delitos sexuales, cuya entrevista sea videograbada y en frente del juez, fiscal y defensor por medio de un sistema de circuito cerrado de televisión o cámara Gesell. El entrevistador puede cumplir con este objetivo porque está entrenado en entrevistas a niños y niñas víctimas de delitos sexuales y violentos y podrá hacer preguntas que justamente apunten a su credibilidad y a la demostración de eventuales contradicciones, con un rigor y técnica quizás más elevado que el que pudiese realizar el defensor en persona. Asimismo, podrá hacer las preguntas que el defensor le indique, y todo esto de una forma que no agreda su integridad sicológica.

Es cierto que el tono de voz, el contexto de exposición y la agresividad de las preguntas no serán las mismas, pero ello se justifica porque no es la única manera de lograr los objetivos del contrainterrogatorio y, por otro lado, exponer al niño o niña 
a un contrainterrogatorio directo, tal cual se puede hacer con una víctima adulta, es sencillamente desconocer sus características especiales y discriminarlo por ello, vulnerando asimismo su integridad sicológica. El contrainterrogatorio debe adaptarse a las especiales características de la población infanto-juvenil, no porque sean «débiles jurídicos», desafortunada expresión que descalifica a la niñez como incapacitada. Así como lo indica Enrique Varsi, al afirmar que

para la Ley General de la Salud (artículo 5), en concordancia con el artículo 4 de la Constitución, son sujetos de derecho especiales en el cuidado de la salud: el niño, la madre, el adolescente, el discapacitado, el anciano en situación de abandono social. Es responsabilidad del Estado velar por el bienestar general (entiéndase salud) de estos seres humanos que, dada sus características físicas o psíquicas, se presentan como grupos vulnerables. Como los denomina la doctrina, son débiles jurídicos o sujetos vulnerables que necesitan de protección especial, una tutela (venia debilium) respecto de acciones que pueden perjudicarlos (Varsi Rospigliosi, 2017: 213-225).

Por el contrario, es porque son especiales, tienen caracteres diversos a los adultos y, por ende, la intervención, en este caso el contrainterrogatorio, también debe ser especial. Por lo demás, esta especial consideración ya ha sido consagrada en el Código Procesal Penal, aunque de una forma evidentemente insuficiente, en la disposición del artículo 310, el que establece que las preguntas de los intervinientes deberán ser dirigidas al menor de 18 años por intermedio del presidente de la Sala. ${ }^{5}$

Es necesario compatibilizar el debido proceso con la protección de la integridad sicológica de los niños y niñas víctimas de delitos sexuales. Ambos son derechos humanos que deben respetarse, por lo que no es válido el atropello de la integridad sicológica de los niños so pretexto de la garantía del debido proceso. La entrevista videograbada de niños y niñas por expertos entrevistadores constituye una forma válida y adecuada para que se respeten ambos derechos humanos, tal como se ha evidenciado en la experiencia y legislación comparada de países como España, Reino Unido, Australia, Israel y Bélgica, entre otros. Esta experiencia nos muestra que se debe implementar un protocolo de entrevistas, el cual ha sido desarrollado fundamentalmente en países de habla inglesa, pero que tiene elementos en común, como el uso de un lenguaje adecuado y el establecimiento de una relación de confianza con el niño, entre otros. Como describe la fundación Amparo y Justicia:

Más allá de las características particulares de cada protocolo, estos tienen en común la mayoría de sus elementos, cuyos fundamentos se encuentran en la literatura científica relativa a los principios de la memoria y los procesos cognitivos sociales.

5. Artículo 310 del Código Procesal Penal: «Testigos menores de edad. El testigo menor de edad solo será interrogado por el presidente de la sala, debiendo los intervinientes dirigir las preguntas por su intermedio». 
Dentro de los criterios u objetivos comunes se encuentra la importancia del establecimiento de una relación de confianza con el niño, niña o adolescente (rapport); la preferencia por la utilización de preguntas abiertas evitando el uso de preguntas sugestivas y el uso de un lenguaje adecuado para el niño, niña y adolescente (Amparo y Justicia, 2020: 147).

\section{«La víctima debe declarar en el juicio oral»}

Otra argumentación contra el sistema de entrevista videograbada es aquella que exige, como garantía del debido proceso, la comparecencia de la víctima en el juicio oral. Se trata este de un argumento falaz, no solo porque no es una obligación legal la comparecencia de la víctima si ni la Fiscalía ni la defensa la presentan como testigo, sino que también porque nuestro Código Procesal Penal ya contempla la posibilidad de que el niño o niña víctima de un delito sexual declare en forma anticipada, de conformidad a lo dispuesto en el actual artículo 191 bis del Código Procesal Penal.

Es sabido también que la comparecencia de un niño a las salas de audiencia de un tribunal trae consigo numerosos obstáculos producto de las características propias del lugar, así como el actuar de los adultos que en dichas circunstancias rodean al niño:

Otro aspecto a considerar es el relacionado con el impacto negativo que producen ciertas características de la misma sala de audiencias en la calidad y cantidad de información entregada por los niños, niñas y adolescentes. Las salas de los tribunales tienen por objeto generar una sensación de solemnidad, dada la lejanía y asimetría en la posición que ocupan los distintos intervinientes, por lo que no constituyen un lugar idóneo para las declaraciones de los niños niñas y adolescentes. Estudios con niños y niñas no víctimas concluyen que, además de presentar respuestas de estrés, la precisión y cantidad de información que ellos entregan al ser entrevistados en una sala de audiencias simulada es menor, en comparación con salas especiales adyacentes o entornos menos intimidantes (Amparo y Justicia, 2020: 183-184).

Ha sido el propio Ministerio Público el que institucionalmente ha reconocido como una buena práctica la aplicación de la ley de entrevista videograbada en sede judicial, evitando el someter a los niños a las mismas condiciones que enfrentan los adultos en el mismo procedimiento:

Por su parte, la declaración judicial tiene como fin que la persona menor de edad preste declaración en juicio en una sala en la que solo estarán presentes el entrevistador y la niña o niño. Los adolescentes, cuando así lo manifestaren, podrán declarar en el juicio sin la intervención de entrevistador. La declaración se desarrollará bajo la dirección, control y supervisión del juez presidente del tribunal o del juez de garantía, en su caso, en una sala distinta a aquella en que se realice la audiencia y deberá realizarse de manera continua en un único día (López Hernández, 2018: 50). 
«Se puede ver afectado el derecho a la defensa»

Si el derecho a la defensa consiste en exponer al niño al maltrato sicológico, para así obtener contradicciones y falta de credibilidad como testigo, entonces esta afirmación es correcta. Pero, desde luego, carece de legitimidad, pues no es justificable bajo ningún respecto la afectación de la integridad sicológica de los niños y niñas, quienes están amparados por un especial manto de protección, que es su mejor interés y los derechos del niño que el Estado de Chile se ha obligado a respetar desde hace ya 30 años. Como ya se ha sostenido, los derechos humanos deben ser interpretados y aplicados de una forma tal que permita su pleno goce, por lo que no es admisible la negación de los derechos del niño so pretexto de la protección de otro derecho humano.

La entrevista videograbada da garantías de igualdad de armas, nadie tiene más privilegios que otro para interrogar, lo cual se hace a través de un experto en técnicas de entrevistas. Asimismo, la entrevista es presenciada en tiempo real a través de un espejo unidireccional o de cámaras de televisión, pudiendo ser acompañado de peritos expertos de la defensa y de la fiscalía; y el video, con posterioridad, puede ser metapericiado las veces que se requiera, sin requerir que el niño o niña entregue otra vez su relato, con lo que se evita la victimización secundaria y se garantiza de igual forma el derecho a la defensa. Sin embargo, con posterioridad a la entrada en vigor de la Ley 21.057, se siguen estudiando las colisiones de derechos en materia de defensa del imputado, como puede apreciarse en Torres Hermosilla (2019: 1), cuando afirma:

Esta investigación tratará la introducción de la entrevista investigativa videograbada, realizada a niños, niñas y adolescentes víctimas de delitos sexuales y otros delitos graves, en el juicio oral, como una forma de adecuar el proceso penal en dichos casos, con el objetivo de erradicar la victimización secundaria sufrida por aquel grupo de menores en su paso por el sistema de justicia, especialmente en reemplazo de su comparecencia en juicio, y la posibilidad de que ello vulnere el debido proceso y el derecho a defensa del imputado, en contraposición a la contingente predominancia del interés superior del niño. Esto, en el marco de la reciente publicación de la Ley 21.057 en Chile y de la masiva implementación de la entrevista investigativa videograbada en el derecho comparado.

\section{«Disminuir la cantidad de declaraciones de los niños y niñas víctimas de delitos sexuales afectará la investigación»}

Desde el Ministerio Público surgieron también algunas voces que ponen en cuestionamiento la reducción de las declaraciones de los niños y niñas víctimas de delitos sexuales a solo dos oportunidades o tres si son mayores de 14 años. Claro, piensan que si un fiscal tiene más entrevistas, tiene más posibilidades de aclarar los hechos, pues puede ser que el niño o niña no dé todos los detalles del hecho, calle y no diga 
cosa alguna, o aparezcan datos relevantes que no puedan ser contrastados con otra declaración, lo cual disminuye las posibilidades de éxito de la causa. Pero justamente allí está el error. Es abundante la experiencia comparada que ha demostrado lo contrario: menos es más en este caso ${ }^{6}$. Más declaraciones no implican mejores declaraciones; más bien, implican mayor posibilidad de contradicciones y de incorporación de elementos ajenos a los hechos en realidad ocurridos. Desde un punto de vista netamente práctico, la entrevista única mejora las posibilidades de que el relato del niño o niña tenga alguna validez e impacto práctico en la investigación y posterior proceso penal, disminuyendo los riesgos de sugestión y, por tanto, de que se «contamine» su relato, haciéndolo por ende más creíble. Asimismo, la entrevista permanece en el tiempo a través de su grabación, lo que ayuda a conservar los detalles verbales y no verbales de la declaración, con lo que se puede enfrentar de mejor forma, por ejemplo, el fenómeno de la retractación, y dar importancia al lenguaje corporal, pues muchas veces el silencio de los niños, en su cuerpo, actitud, dibujos, juegos y comportamiento dicen más que mil palabras.

Por otro lado, habiendo despejado la utilidad práctica que tiene la entrevista videograbada en niños y niñas víctimas de delitos sexuales, cabe también hacer énfasis en el carácter vulnerador de la integridad sicológica de estos niños y niñas que tiene la reiteración de esta declaración, una y otra vez, ante distintos profesionales. La llamada victimización secundaria se produce como resultado de un actuar insensible y poco respetuoso del derecho a la integridad sicológica de las víctimas que se acercan a las instituciones del Estado a buscar protección, no agresión y daño, incluso a pretexto de una más acertada investigación. Y es que aun cuando así fuese -que no lo es-, el desarrollo de la investigación penal tiene límites, no se puede hacer a cualquier costo. Por ello, por ejemplo, las medidas intrusivas que afectan la intimidad, consistentes en el allanamiento de un hogar, la intervención de teléfonos o de correos electrónicos, requieren de una expresa autorización judicial porque el atropello de esos derechos fundamentales debe estar debidamente justificado. Es decir, la investigación que lleva a cabo el fiscal adjunto tiene límites demarcados por la Constitución y los tratados internacionales de derechos humanos (recordemos que estos constituyen un límite al ejercicio de la soberanía), límites que no puede sobrepasar, pues de lo contrario actuaría en contra del ser humano; nuestra Carta Fundamental establece que el Estado - y el Ministerio Público es parte del Estado- está al servicio de la persona humana, no al revés.

6. Esta experiencia ha sido sistematizada en las cuatro versiones del Seminario Internacional sobre Agresiones Sexuales Infantiles, organizadas por la Fundación Amparo y Justicia, cuyos materiales y documentos pueden descargarse en su sitio web, amparoyjusticia.cl. 


\section{«Es extraño que el fiscal no pueda entrevistar a la víctima»}

Otro argumento que se esgrimió es que el fiscal debe interrogar personalmente a la víctima, pues solo así se puede formar convicción en su investigación. Hay que descartar también este argumento, pues el Ministerio Público dirige la investigación, no la ejecuta directamente. Y si bien puede citar a las víctimas, testigos e imputados a declarar, muchas veces delega esa función en Carabineros o la Policía de Investigaciones, pues son estos los profesionales idóneos y preparados para llevar adelante la investigación en forma material.

Al tratarse de niños y niñas, entonces, el fiscal deberá confiar en lo que profesionales idóneos y preparados pueden hacer, confiando en que es la mejor vía para obtener buenos relatos, de calidad, tomados por quienes se han entrenado para ello. Muchas veces los abogados, y entre ellos los jueces, defensores y fiscales, creemos que podemos hacer gestiones respecto de las cuales no tenemos formación ni entrenamiento. No somos expertos entrevistadores, y tal como se ha observado en la experiencia comparada, quienes entrevistan a los niños tienen largos períodos de entrenamiento y formación, la cual es necesaria para poder hacer buenas entrevistas que respeten el derecho del niño a ser oído, que respeten su integridad sicológica, que reduzcan al mínimo la victimización secundaria y que generen productos procesales o investigativos valiosos para las partes.

\section{Exposición dogmática y crítica de los principales elementos de la Ley 21.057}

\section{¿Quién es el entrevistador?}

El entrevistador es el técnico o profesional quien, debidamente entrenado en una específica metodología de entrevista y acreditado por la autoridad competente como tal, materializa la entrevista videograbada en cualquiera de sus oportunidades procesales.

Se trata de un técnico o profesional, por cuanto no se requiere un título de educación superior en específico, como, por ejemplo, detentar el título de sicólogo, siquiatra o trabajador social. A diferencia de lo que ocurre con un consejero técnico, que es «un auxiliar de la administración de justicia, un profesional trabajador social, orientador familiar o sicólogo con formación de posgrado acreditada en materia de infancia, adolescencia y familia, que realiza labores de asesoría al juez de familia» (Henríquez Galindo, 2017: 138), la Ley 21.057 de entrevistas videograbadas no prescribe que se deba tratar de alguna persona con título profesional específico, por lo que ni siquiera se requiere un título universitario, sino que puede ser perfectamente una persona con título técnico profesional. Lo anterior se debe a que, en definitiva, lo que importa para el ejercicio de la función de entrevistador de esta ley no es la formación académica o profesional del entrevistador, como si lo es su pericia o experticia 
práctica en la ejecución correcta de una técnica de entrevista determinada. Así, es perfectamente posible que el entrevistador sea un abogado, un juez, un terapeuta ocupacional, etcétera. Lo relevante es la técnica, y es en función de ella que se configura el entrevistador:

Algunos autores recalcan que, más que una disciplina determinada, lo que se requiere son personas con habilidades y conocimientos específicos en la técnica de entrevista investigativa, los cuales se adquieren a través de un proceso de formación apto para distintos tipos de profesiones (Amparo y Justicia, 2020: 133).

Debe ser, además, acreditado por la autoridad competente. La Ley 21.057 establece un sistema de acreditación periódica que acredita a quienes pueden presentarse como entrevistadores en un proceso penal determinado, en el que deben pasar distintas evaluaciones y requisitos que tienen como objeto asegurar sus competencias técnicas.

El entrevistador es quien, en definitiva, materializa la entrevista, vale decir, el entrevistador no existe como un auxiliar de la administración de justicia, orgánicamente constituido, sino que se constituye como tal en la entrevista misma. Es cierto que debe constar su acreditación en la respectiva nómina oficial de entrevistadores del Ministerio de Justicia, pero ello no significa que aquellas personas son «entrevistadores», en tanto no ejerzan la función de entrevistar. Dicha nómina solo los habilita para ejercer la función, pero el «entrevistador» no constituye per se una figura orgánica en sí misma. El profesional de la Policía de Investigaciones o Carabineros, el juez, consejero técnico o profesional de la Unidad Regional de Atención a Víctimas y Testigos (URAVIT) será entrevistador solo en la medida en que ejerza dicha función. Antes solo se podrá afirmar que se encuentran «habilitados» para entrevistar, en el marco de la Ley 21.057.

Cabe agregar que estos requisitos son copulativos, no se superponen unos a otros, y deben manifestarse en conjunto al momento de designar al entrevistador y materializar la entrevista. No basta con estar formalmente en la nómina, pues si quien practica la entrevista denota graves falencias técnicas en la forma en que debiera desarrollar la entrevista, bien puede interrumpirse, por considerar que no se está frente a un entrevistador idóneo y se requiere nombrar a uno que esté debidamente capacitado en la técnica de entrevista. El artículo 6 de la Ley en comento establece que el entrevistador de la entrevista investigativa será designado por el fiscal y, en este caso, es el mismo fiscal quien debiera tomar esta decisión, dando plenas garantías a todas las partes, sin perjuicio de remitir los antecedentes al Ministerio de Justicia para que sea tomado en cuenta respecto de su acreditación como entrevistador. En el caso del entrevistador de la declaración judicial, su designación está regulada en el artículo 15 de la misma ley, que le entrega dicha labor al juez de garantía, que en caso de falencia del entrevistador debiese ser, naturalmente, quien designe otro más idóneo. En am- 
bos casos, la idoneidad del entrevistador a designar debiese estar centrada en el cumplimiento de los estándares que exige el Ministerio de Justicia para su acreditación, así como en su experiencia profesional y evaluaciones positivas de su ejercicio como entrevistador en años anteriores, prefiriéndose siempre aquel o aquella entrevistadora que reúna las mejores condiciones del listado disponible.

Es más, no solo destrezas profesionales, académicas o técnicas debe detentar el entrevistador. También debe contar con habilidades personales de escucha y paciencia para comunicarse efectivamente con el entrevistado. En efecto, se requiere de empatía y herramientas emocionales y sociales que le permitan alcanzar los objetivos de la entrevista, siguiendo el respectivo protocolo:

Un estudio encontró que algunas características de los entrevistadores influirían en su propio desempeño, la inteligencia emocional (empatía, manejo de emociones, flexibilidad, entre otros) y simpatía influirían positivamente en la adherencia al protocolo, en un mayor uso de preguntas abiertas y en la obtención de una mayor cantidad de detalles por parte de los niños, niñas y adolescentes víctimas, mientras que el neuroticismo (ansiedad y preocupación) estaría negativamente relacionado con dichas prácticas (Amparo y Justicia, 2020: 134).

\section{¿Quién es el entrevistado?}

Ante todo, y aunque parezca una obviedad, se trata de una persona, de un sujeto de derechos. Es importante destacarlo, puesto que, hasta no muy poco, la declaración de la víctima era simplemente otro medio de prueba más, sobre el cual se podían ejercer todo tipo de medidas, solicitudes y reiteración de declaraciones, con un trato que la dejaba más bien como un objeto del proceso, revictimizada, no como sujeto de derechos. Desde el momento en que la víctima es reconocida como sujeto de derechos y se reconoce también que su integridad sicológica es igual de relevante que la persecución penal o el debido proceso, nace la necesidad de generar espacios, condiciones y personal adecuado para tomar esta entrevista armonizando los fines y derechos de todos los intervinientes con los derechos fundamentales de la víctima. Así lo expresan los principios que detalla el artículo 3 de la Ley 21.057, en especial su letra f), cuando señala que todo niño, niña o adolescente es una persona valiosa y, como tal, se debería respetar y proteger su dignidad individual, sus necesidades particulares, sus intereses y su intimidad. Esta triple distinción que hace la norma se armoniza con la letra a) del mismo artículo y que sostiene como principio el interés superior del niño, brindándole un contenido más concreto, y protegiéndolo especialmente cuando establece que los funcionarios públicos que vulneren tal principio incurren en una grave falta a los deberes funcionarios.

El artículo 1 de la Ley 21.057 establece que las personas que podrán ser entrevis- 
tadas bajo tal marco normativo son niños, niñas y adolescentes que hayan sido víctimas de los delitos que allí se indican. Al referirse a esta especial categoría de personas, remite de inmediato a lo prescrito por la Convención sobre Derechos del Niño, que es ley de la República por Decreto Supremo 830 del Ministerio de Relaciones Exteriores de 1990, y que en su artículo 1 prescribe que son niños los menores de 18 años. La Convención no distingue niños y adolescentes, pero la relevancia de distinguir adolescentes en este marco normativo dice relación con la autonomía progresiva en el ejercicio de sus derechos, que detentan todos los niños, que se desprende del artículo 5 de la citada Convención y que es cada vez mayor a medida que avanzan a la mayoría de edad. Es en ese sentido que debe interpretarse la precisión que hace el artículo 1 en su inciso tercero, al distinguir como niños a los menores de 14 años y como adolescentes a los mayores de 14 y menores de 18 años. Resulta igualmente coherente con la misma distinción que, para fines punitivos, hace la Ley 20.084 al definir quiénes son adolescentes. Por otro lado, se refiere a los niños y niñas, queriendo con ello declarar desde un comienzo la perspectiva de género que impregna toda la ley y que exige tener en cuenta esta especial mirada.

Para la aplicación de la entrevista videograbada, los niños, niñas y adolescentes deben ser víctimas o testigos de los delitos que expresamente señala el mismo artículo 1, a saber, los contemplados en los párrafos 5 y 6 del título séptimo del libro segundo del Código Penal, teniendo en cuenta que, para efectos de esta ley, las víctimas deben ser siempre menores de 18 años: violación propia, que corresponde a la violación a un mayor de 14 años; violación impropia, a un menor de 14 años; estupro, que se aplica a los mayores de 14 años; acceso carnal sodomítico a un mayor de 14 años; abuso sexual calificado por uso de objetos o animales a un menor de 18 años; abuso sexual propio a un mayor de 14 años; abuso sexual impropio a un menor de 14 años; acciones de significación sexual ante un menor de 14 años; promoción o facilitación de la explotación sexual de menores de 18 años; obtención de servicios sexuales de menores de 18 años, de carácter residual.

$\mathrm{Y}$ aquellos delitos contemplados en el artículo 141, incisos cuarto y quinto (secuestro por más de quince días o con grave daño; homicidio, violación, violación sodomítica, castración, mutilación de miembro importante o menos importante, lesiones graves gravísimas dejando al ofendido demente, inútil para el trabajo, impotente, impedido de algún miembro importante o notablemente deforme, producidos con motivo u ocasión del secuestro); artículo 142 (sustracción de menores); artículo 372 bis (homicidio producido con ocasión de la violación); artículo 374 bis (comercialización, difusión y adquisición maliciosa o almacenamiento de material pornográfico en cuya elaboración hubieran sido utilizados menores de 18 años); artículo 390 (parricidio y femicidio); artículo 391 (homicidio simple y calificado); artículo 395 (castración); artículo 397 número 1 (lesiones graves si el resultado es quedar demente, inútil para el trabajo, impotente, impedido de algún miembro importante o notable- 
mente deforme); artículo 411 bis (tráfico de migrantes); artículo 411 ter (promoción y facilitación particular de la entrada o salida del país para ejercer la prostitución); artículo 411 quater (trata de personas propia y trata impropia de menores); y artículo 433 número 1 (homicidio, violación, castración, mutilación de miembro importante o miembro menos importante, lesiones graves si el resultado es quedar demente, inútil para el trabajo, impotente, impedido de algún miembro importante o notablemente deforme, con motivo u ocasión del robo con violencia o intimidación), todos del Código Penal.

Cabe precisar que debe tratarse de víctimas, tal como lo define el Código Procesal Penal en su artículo 108, o testigos. Es en esa especial calidad procesal que procede la aplicación de esta ley, a su respecto, en tanto víctimas o testigos, según lo disponen los artículos 8 y 26 de la Ley 21.057. De esta forma, se considera víctima, en primer lugar, al ofendido por el delito. Si el ofendido directo ha fallecido, se considerará víctima: i) al cónyuge o al conviviente civil y a los hijos; ii) a los ascendientes; iii) al conviviente; iv) a los hermanos; y v) al adoptado o adoptante. Este listado es también un orden de prelación, es decir, «la intervención de una o más personas pertenecientes a una categoría excluye a las comprendidas en las categorías siguientes».

Sobre este punto surgen algunos problemas que ya se pueden anticipar. Resulta patente la discriminación de los adoptados, que es contraria a la expresa disposición legal del artículo 179 del Código Civil y del artículo 1 de la Ley 16.620 sobre adopción de menores, por la cual se entiende que, para todos los efectos legales, el adoptado es hijo del adoptante. Sin embargo, en este listado queda al final del orden de prelación, lo que genera una discriminación evidente. Se observa aquí un conflicto de leyes que debe ser resuelto conforme el interés superior del niño y el principio de no discriminación, contenidos en el artículo 3 de la Convención sobre Derechos del Niño y en la llamada ley Zamudio, Ley 20.609, así como en la Declaración Americana de Derechos Humanos en su artículo 24.

Del mismo modo, es imprescindible considerar nuestra propia Carta Fundamental en sus artículos 1 y 19 numeral 2, que prohíbe la discriminación arbitraria. Supongamos el caso de que las víctimas de un delito cuyo ofendido directo ha fallecido son niños y niñas que detentan la calidad de hijos biológicos y adoptivos. Sería absurdo y contrario a derecho brindarles a unos un trato de víctima y a los otros no por ser excluidos en este orden de prelación. Es sin duda una norma abiertamente inconstitucional. Debe aplicarse aquí con preferencia la regulación de la Ley 21.057 por sobre la norma del Código Procesal Penal, que es por lo demás mandato expreso del artículo 2 de la referida ley, que le otorga carácter especial.

Por otro lado, es posible que niños y niñas caigan en una u otra categoría. Entre los hijos y los hermanos de la víctima, puede suceder que haya niños en ambas categorías. ¿Quedarán los niños hermanos de la víctima excluidos de esta norma? Nuevamente se observa una discriminación arbitraria e inconstitucional que debe ser 
resuelta con norma de rango constitucional e instrumentos legales e internacionales de derechos humanos, para brindar la debida protección que promueve esta ley de entrevista videograbada.

En cualquier caso, de presentarse el problema, debe aplicarse el artículo 2 de la Ley 21.057, que establece una aplicación preferente de sus preceptos frente al Código Procesal Penal. Por lo demás, los principios expresados en el artículo 3 de la citada ley debiesen ser suficientes para considerar a todas las víctimas y testigos menores de 18 años amparados por esta ley, por ser especial y posterior a la norma del Código Procesal Penal, y por ser coherente con la Convención sobre Derechos del Niño, sin atender por tanto al orden de prelación.

\section{La entrevista}

Esta ley establece dos tipos de entrevistas. Si hacemos un poco de historia, podemos advertir que en un comienzo se hablaba de «entrevista única videograbada», puesto que los primeros proyectos justamente apuntaban a que se prescindiera de la declaración de la víctima en el juicio oral, ya que sería suficiente la declaración inicial del niño, tomada por profesionales expertos entrevistadores, la cual sería grabada y utilizada en el juicio oral. Los beneficios de este tipo de entrevistas se materializaban en la prontitud de la intervención y la proximidad del relato con los hechos denunciados, lo que evitaba su contaminación con elementos externos que lo distorsionaran con el paso del tiempo, aumentando la calidad de la declaración, así como la protección de la víctima de los procesos revictimizadores propios de la reiteración de este relato. Una idea que no es original, puesto que ya funcionaba de esa forma en Israel, 7 Bélgica $^{8}$ y otros países. ${ }^{9}$ Sin embargo, se presentaron con rapidez los argumentos en contra, que señalaban que el persecutor se vería impedido de resolver contradicciones, aclarar dudas o indagar en más detalles si se le limitaba a una sola la declaración de la víctima. Por otro lado, desde la defensa se criticaba que no se brindaba de una oportunidad de contrainterrogar este relato grabado y de confrontar a la víctima para demostrar sus contradicciones y errores, lo que perjudicaba a la defensa del imputado. Del mismo modo, los defensores de la oralidad y la inmediación arguyeron que

7. En Israel existe un procedimiento diferenciado en el caso de la comisión de delitos sexuales contra menores de 14 años. Para los adolescentes el procedimiento es el mismo que para los adultos. Las investigaciones se llevan a cabo por un trabajador social especialmente capacitado, denominado investigador infantil. Toda la investigación es documentada en forma íntegra por el perito, en video o subsidiariamente en audio o escrito.

8. En Bélgica la declaración de los niños y adolescentes es grabada en video y reemplaza su comparecencia en el tribunal (video y el acta de la interrogación).

9. «Experiencia internacional de formación en entrevista investigativa en modalidad online», Fundación Amparo y Justicia, noviembre de 2020, disponible en bit.ly/3ujzkfo. 
una imagen videograbada no reemplaza la declaración presencial, pues obstruía al juez de importante información al no apreciar de manera directa el relato, sin poder adquirir por sus propios sentidos una idea del lenguaje verbal y corporal que expresa la víctima, a través de una grabación. Todas estas críticas llevaron al legislador a derivar, desde la idea de una declaración videograbada única, al texto que hoy rige como ley y que establece dos tipos de entrevistas, con diversos fines procesales: la entrevista investigativa y la entrevista judicial.

\section{La entrevista investigativa}

Es aquella que tiene por objeto recabar información, lo más próxima a la denuncia o develación, que aporte antecedentes o datos concretos para determinar la forma en que ocurrieron los hechos y sus posibles partícipes, o bien, descartar su ocurrencia.

Esta entrevista está supeditada a los objetivos que se propone el Ministerio Público, quien tiene a su cargo esta etapa del procedimiento, la que en la mayor parte de los casos no estará judicializada. Es necesario recordar que según su ley orgánica constitucional, el Ministerio Público debe investigar «con igual celo no solo los hechos y circunstancias que funden o agraven la responsabilidad del imputado, sino también los que le eximan de ella, la extingan o la atenúen» (Ley Orgánica Constitucional 19.640, artículo 3, inciso primero). Así, pues, en esta entrevista se busca dilucidar qué ocurrió en palabras de la víctima y quiénes pudieron participar. No obstante, aun si son estos los fines de una entrevista investigativa, ello no quiere decir que siempre se alcance tal objetivo, por múltiples razones. Las más importantes son las relativas a las dificultades que el propio niño, niña o adolescente plantee por razones de salud mental, bien omitiendo información, bien negándose a declarar. Por otra parte, es posible que brinde un relato, pero que este no se enmarque en un hecho que reviste caracteres de delito, lo que puede implicar la derivación del caso a tribunales de familia para dar cuenta de una posible vulneración de derechos que amerite una medida de protección en esa sede.

En el evento de que se reúna información útil para investigar los hechos denunciados, la entrevista investigativa será sin duda la herramienta principal para que el fiscal adjunto lleve adelante su tarea indagatoria. $\mathrm{Al}$ respecto, cabe tener presente que

estudios de casos en los que las víctimas fueron entrevistadas siguiendo una correcta técnica de entrevista, reportan efectos significativos en los resultados de las investigaciones y en las decisiones que se tomaron durante el proceso penal. Esto se debería a que la entrevista investigativa, como técnica estandarizada, está diseñada para eliminar el uso de preguntas sugestivas y disminuir aquellas que potencialmente podrían afectar la precisión de los relatos entregados por los niños, niñas y adolescentes entrevistados. De esta forma, la calidad de esta entrevista influye en la percepción de los actores del sistema, aumentando su confianza en la fiabilidad 
o credibilidad de las declaraciones de los niños, niñas y adolescentes (Amparo y Justicia, 2020: 72).

Pero lo más destacable es que, por medio de esta técnica, se garantizan de forma efectiva los derechos del niño en el proceso penal, su derecho a la integridad sicológica y su derecho a ser oído:

El principal beneficio que tiene la entrevista investigativa es que esta se realiza en condiciones que permitan que niños, niñas y adolescentes puedan ejercer efectivamente tanto su derecho a un trato digno y comprensivo, como su derecho a participar y hacer oídos, todos consagrados en la Convención de los Derechos del Niño. [...] Otro beneficio es la reducción del número de entrevistas a la que son sometidos los niños, niñas y adolescentes durante el proceso. Esto se debe a que la técnica utilizada permite obtener un relato más completo y preciso, que es registrado a través de una videograbación que puede utilizarse en reemplazo de la comparecencia de la víctima a otras instancias, sean investigativas o proteccionales (Amparo y Justicia, 2020: 73-74).

\section{La entrevista judicial}

Esta es una entrevista cuyas características y objetivos difieren en forma radical de la primera. Recordemos que se inserta en una etapa previa al proceso propiamente tal, cuando aún no se ha presentado la acusación ni el auto de apertura que da inicio al juicio oral, es decir, durante la fase investigativa del procedimiento, y que es posterior a la entrevista investigativa descrita en el punto anterior. En esta entrevista tanto el fiscal como el defensor tienen la oportunidad de hacer preguntas a la víctima y el juez de garantía puede presenciarla, lo que da así todas las condiciones de imparcialidad, pues habrá derecho a contradicción frente a un juzgador imparcial, al ser posible la participación del defensor ante un juez que podrá juzgar la pertinencia de las preguntas. Esta entrevista debe llevarse a cabo en una sala especial, con la sola presencia del entrevistador y el niño, niña o adolescente. Su finalidad no es indagar sobre los hechos y posibles partícipes, sino brindar a todas las partes el acceso a un relato y la posibilidad de plantear preguntas a la víctima, a la vez que se protege su integridad sicológica. La entrevista judicial dispone de todas las herramientas para respetar el debido proceso y la igualdad de armas de las partes, así como asegurar la integridad emocional de la víctima.

Por regla general, la entrevista videograbada investigativa no debería ser exhibida en el juicio oral. No obstante, existen ciertas hipótesis en las que puede utilizarse la entrevista investigativa videograbada en reemplazo de la declaración judicial, según lo dispuesto en el artículo 18 de la Ley 21.057. El tribunal podrá permitir la reproducción de la entrevista videograbada solo: cuando el niño, niña o adolescente que hizo 
la entrevista hubiese fallecido o caído en incapacidad mental o física que le inhabilite para comparecer en juicio; cuando se trate de niños que durante su comparecencia en juicio hubiesen caído en una incapacidad grave, síquica o física para prestar declaración; cuando habiendo declarado ya el niño, niña o adolescente en juicio o en audiencia anticipada, se quiera complementar su declaración o demostrar contradicciones y siempre y cuando el niño, niña o adolescente ya hubiese terminado de declarar, no pudiendo reanudar su declaración; y cuando se haya citado al entrevistador para que dé cuenta de la metodología empleada.

También es posible que se practique la entrevista judicial de manera anticipada, si así lo solicitan el fiscal, la víctima, el curador ad litem o el querellante, frente a lo cual el juez citará a una audiencia para debatir su procedencia, según lo dispone el artículo 16 de la Ley 21.057. Decretada la entrevista judicial anticipada, ella debe ser videograbada y será esta grabación la que reemplace su declaración en juicio, salvo que lo solicite el niño, niña o adolescente libre y de manera espontánea, o bien, otro interviniente en virtud de nuevos antecedentes que lo justifiquen y puedan afectar sustancialmente el resultado del juicio.

Toda esta regulación consta en los artículos 13 y siguientes de la Ley 21.057.

\section{Otras funciones del entrevistador}

Es más que obvio que la principal función del entrevistador es precisamente entrevistar; aunque debe precisarse que el entrevistador debe hacerlo de conformidad a los objetivos buscados en cada tipo de entrevista, sea investigativa o judicial. Sin embargo, existen otros deberes que en su calidad de funcionario habilitado para efectuar entrevistas está en la exigencia de cumplir.

En el caso de que, junto con el relato de los hechos denunciados, se afirmen otros que revistan caracteres de delito, en virtud de lo dispuesto en el artículo 4 de la Ley 21.057 y el artículo 173 del Código Procesal Penal, debe igualmente hacer la denuncia, haciendo llegar los antecedentes al fiscal competente. En todo caso, respecto a si el entrevistador es además empleado público, se aplica también lo dispuesto en el artículo 175 letra b) del Código Procesal Penal, respecto del deber de denunciar.

En caso de que se visualice una vulneración de derechos, junto con remitir los antecedentes al fiscal adjunto que investiga, debe informar de tales vulneraciones y de la necesidad de oficiar al juzgado de familia competente para que decrete una medida de protección y medidas cautelares acordes.

Tiene el deber de trabajar de manera coordinada con las distintas instancias de protección del niño, niña o adolescente: profesionales de la Unidad Regional de Atención a Víctimas y Testigos, profesionales de las Comisarías de Carabineros y Brigadas de la Policía de Investigaciones especializadas, profesionales de programas y colaboradores acreditados del Sename, profesionales de la salud del Cesfam respecti- 
vo, peritos forenses del Servicio Médico Legal y de otras instituciones, además de los consejeros técnicos de Tribunales de Familia:

Por esta razón, los entrevistadores forenses desempeñan un papel importantísimo en la investigación del maltrato infantil. La entrevista investigativa típicamente pone en marcha el procedimiento penal y/o una variedad de otras intervenciones para los niños y las familias. La información que se genere a partir de las entrevistas investigativas puede afectar poderosamente la decisiones legales y administrativas, las que a su vez pueden afectar de manera insondable las vidas de los niños, las familias y los implicados; por lo tanto es imperativo que las denuncias de los niños sean claras, coherentes, detalladas y precisas (Malloy y otros, 2010: 2).

\section{Comparación con la entrevista reservada de los Tribunales de Familia}

Tal como se ha indicado, la entrevista no es una simple declaración, ni pericia o contención emocional. Tampoco se encuadra en la entrevista reservada de la Ley de Tribunales de Familia, por cuanto sus objetivos son distintos. Si bien en ambos casos se da cumplimiento al derecho del niño a ser oído respecto de cualquier procedimiento que le afecte, la entrevista investigativa tiene por finalidad acumular datos que puedan orientar una investigación penal. En cambio, la entrevista reservada de los tribunales de familia tiene por fin garantizar la protección de sus derechos frente a los intereses de otros o frente a situaciones de vulneración de derechos.

Por otro lado, el espectro de causas por las que se puede entrevistar de manera reservada a un niño, niña o adolescente en los tribunales de familia es mucho más amplio, ya que la entrevista investigativa solo procede cuando la víctima ha sido objeto de ciertos tipos de delitos prescritos en la ley. Sin embargo, ambos tipos de intervenciones pueden coincidir, es decir, los mismos hechos pueden dar lugar a ambos tipos de entrevistas. En el caso de que así suceda, igualmente el objeto de ambas es diverso por las razones ya señaladas, aunque cabe preguntarse si acaso, habiendo procedido una entrevista investigativa, se hace necesario llevar a cabo una entrevista reservada en los juzgados de familia. Tomando como premisa que en este tipo de casos debe evitarse la victimización secundaria, la reiteración de la entrevista puede resultar contraproducente. Por tanto, en el caso que así se presenta, tanto el entrevistador investigativo como el consejo técnico deberán estar coordinados y definir si es necesario hacer la entrevista reservada o bien se puede omitir, aunque será finalmente el juez de familia quien determinará a partir de la opinión experta del consejero técnico respectivo, si procede decretarla, teniendo como guía el interés superior del niño en su dimensión procedimental, conforme lo establece la Observación General 14 del Comité de Derechos del Niño de Naciones Unidas. 


\section{Situación actual de la entrevista videograbada y sus perspectivas de futuro}

Implementación durante la pandemia de covid-19

Como es de público conocimiento, a partir de marzo de 2020 se inició en Chile un proceso de cuarentena con encierro total en algunas zonas del país, lo que implica el cierre de tribunales o bien el cese de audiencias presenciales, las que fueron reemplazadas por audiencias virtuales en plataformas como Zoom.

Como se ha indicado, la entrevista videograbada debe hacerse ante un entrevistador acreditado, y en un espacio adecuado para ello. Sin embargo, los necesarios resguardos sanitarios producto de la pandemia de covid- $19^{10}$ afectaron de gran manera la implementación de la Ley 21.057, toda vez que numerosos aspectos de la comunicación no verbal se pierden en un sistema remoto, además de los sesgos y riesgos que conlleva hacer una entrevista como esta a distancia, sin controlar el espacio y las personas que puedan acompañar al niño o niña, la falta de cercanía corporal que muchas veces se requiere para obtener declaraciones que respeten la dignidad y derechos de los niños y que sean útiles a los fines del procedimiento. Por último, también las dificultades técnicas de conexión que puedan aparecer, entre otros aspectos, ponen en duda la eficacia de esta herramienta bajo el contexto referido, atendidos los mismos fundamentos técnicos que siempre suponen la presencia del entrevistador, en contacto con el niño o niña entrevistado y en un espacio protegido y adecuado, sea cual sea su finalidad, investigativa o judicial.

Es en verdad contrario a lo dispuesto en los artículos 20 y 21 de la Ley 21.057 hacer esta entrevista por sistemas de videoconferencia, pues no hay forma en que esta modalidad dé cuenta de todos los requisitos que allí se prescriben de forma obligatoria: protección de la privacidad del niño, niña o adolescente, resguardo de su seguridad y control de la presencia de participantes. No es suficiente que la tecnología permita su grabación y reproducción, pues estos requisitos son de carácter copulativo y condición sine qua non.

Para el año 2020, y según el cronograma de entrada en vigor progresiva de la Ley 21.057 y su Reglamento, debía entrar en vigor el 3 de octubre de ese año en las regiones de Atacama, Coquimbo, Nuble, Biobío, La Araucanía y Los Ríos, sumándose a las regiones de Arica y Parinacota, Tarapacá, Antofagasta, Maule, Aysén, Magallanes y Antártica Chilena que ya iniciaron su implementación el 3 de octubre de 2019. El resto de país se incorporaría finalmente el 3 octubre de 2021. La Ley 21.226, del 21 de septiembre de 2020, prorrogó la entrada en vigor de la entrevista videograbada para su segunda etapa, extendiéndola a 26 meses contados desde su publicación en

10. La pandemia ha tenido su mayor impacto en Chile a partir de fines de febrero de 2020 y se mantiene vigente a la fecha de esta publicación. 
el Diario Oficial, y la tercera etapa a su vez extendiéndola a 42 meses desde la misma fecha. Aun así, ya entró en vigor la primera etapa, y resulta preocupante que en este contexto no se hayan desarrollado lineamientos técnicos públicos y conocidos para enfrentar la contingencia sanitaria que se desarrollará durante todo el año 2021, y muy probablemente parte del año 2022, por cuanto los fundamentos teóricos que sostienen la metodología de la entrevista no se condicen con su realización por medio de plataformas de videoconferencia, lo que puede resultar en mayores vulneraciones a los derechos de los niños, además de frustrar los fines procesales que se persiguen con esta herramienta.

\section{El acceso a las grabaciones: La ley 21.182}

El 22 de abril de 2019, el presidente de la República envió a la Cámara de Diputados un Mensaje con el que inició un proyecto de ley que regula el acceso a los registros de entrevistas investigativas videograbadas y de declaraciones judiciales de la Ley 21.057. El motivo de este proyecto radica en la necesidad de que los evaluadores de los entrevistadores, quienes deben estar en constante capacitación, formación y seguimiento, puedan acceder a los registros de las entrevistas para lograr tales evaluaciones, dado el carácter restrictivo de su contenido, el cual solo era accesible a los intervinientes del proceso, las policías en el cumplimiento de diligencias específicas, los jueces de familia dentro del ámbito de su competencia y los peritos que deban conocerlo con la finalidad de elaborar sus informes, de conformidad al artículo 23 de la Ley 21.057. Es por ello por lo que, para dar acceso a los evaluadores, se presentó este proyecto que finalmente se tradujo en la Ley 21.182, que incorpora un nuevo artículo 23 bis a la Ley 21.057, el cual permite precisamente el acceso de los evaluadores a tales registros.

Esta norma en su momento pasó a control de constitucionalidad en el rol 7.463-19 del Tribunal Constitucional de Chile, por tratarse de una norma orgánica constitucional, al considerar que agrega deberes al fiscal adjunto y agrega otras personas, distintas de los intervinientes, que pueden acceder a las entrevistas, además de disponer de información sensible de las partes. El 8 de octubre de 2019 el organismo declaró que dicha norma es conforme con la Constitución. Los votos disidentes consideran que la norma es una ley simple y no orgánica constitucional.

La Ley 21.182, que entró en vigor el 22 de octubre de 2019, es sin duda un acierto que corrige una omisión que dejaba sin posibilidad de supervisión efectiva a los entrevistadores. Resulta central mantener un sistema de supervisión permanente, con el objeto de procurar que las entrevistas cumplan todos los estándares que exigen los fundamentos técnicos, y de esa forma proteger los derechos y la dignidad de los niños y niñas que se someten a dichas sesiones y, por otro lado, brindar de prueba y medios de investigación de calidad que permitan establecer la existencia o inexistencia de los hechos y participación de los imputados. 


\section{El nuevo escenario: Nuevas formas de investigar y defender}

Con la promulgación y publicación de la Ley 21.057, fiscales, jueces y defensores deberán ajustar sus procedimientos y actuaciones. La entrevista videograbada de niños y niñas víctimas de delitos sexuales traerá consigo importantes consecuencias, pues termina una forma de investigar, defender y juzgar estos delitos que vulnera los derechos y es, por lo demás, ineficaz. Declaraciones reiteradas, mal hechas, llenas de contradicciones y que implican además la reiteración de la vivencia traumática del abuso una y otra vez, son suprimidas y reemplazadas por un sistema adecuado que hace compatible el pleno respeto de las garantías y derechos fundamentales de los niños y niñas víctimas de delitos sexuales con una investigación eficaz y una defensa del imputado resguardada.

Será necesario desarrollar capacitaciones, sensibilización y estudios de implementación, avance y resultados que permitan poner en marcha este sistema de forma adecuada y perfeccionarlo en el transcurso del tiempo. Asimismo, el sistema exigirá contar con un cuerpo de profesionales entrevistadores idóneos y supervisados técnicamente, que brinden seguridad a todos los actores. Estas entrevistas podrán ser observadas también por los peritos de las partes y luego metapericiadas por otros peritos que observen la grabación. En definitiva, se hará compatible la investigación penal de estos delitos, el derecho a la defensa del imputado y los derechos del niño o niña víctima de un delito sexual, constituyéndose un gran avance en el reconocimiento de la calidad de sujetos de derechos de los niños, niñas y adolescentes.

Recordemos que un niño o niña abusado sexualmente ha sido negado en su calidad de sujeto de derechos, y ha sido negado en su dignidad. El Estado debe primero que todo devolverle esa dignidad, reconociendo su calidad de sujeto de derecho, respetando su dignidad, escuchándolos, asegurando que no se reiterará innecesariamente su declaración y protegiendo su salud mental.

El Estado está al servicio de los niños y niñas, y no al revés. El Estado debe reconocer su dignidad y su calidad de sujetos de derechos, no tratarlos como meros objetos de prueba.

\section{La entrevista videograbada como herramienta de justicia terapéutica}

La justicia terapéutica:

Se concentra en el impacto de la ley sobre la vida emocional y el bienestar sicológico de las personas. Es un enfoque que considera a la ley (normas jurídicas, los procedimientos legales y los roles de los actores legales) como una fuerza social que a menudo produce consecuencias terapéuticas o antiterapéuticas. Es decir, que generan un beneficio o un perjuicio al conflicto y a las personas que lo experimentan. No sugiere que los aspectos terapéuticos de la ley sean más importantes que otras consecuencias o factores, pero sí que el papel de la ley como un potencial agente 
terapéutico debe ser reconocido y estudiado sistemáticamente. El término fue utilizado por primera vez por el profesor David Wexler, de la Universidad de Arizona, en un documento publicado en el Instituto Nacional de Salud Mental en 1987 y fue más tarde acuñado junto al profesor Bruce Winick, de la Universidad de Miami. A principios de la década de los noventa, los académicos del área del derecho comenzaron a utilizar el término para referirse a ámbitos de la ley y de la salud mental. Sin embargo, el enfoque [de justicia terapéutica] pronto comenzó a extenderse más allá de las leyes de salud mental hacia los ámbitos del derecho penal, familiar y juvenil, así como también hacia las leyes de responsabilidad civil, la discapacidad, el derecho constitucional, entre otros. ${ }^{11}$

Es en este sentido que la entrevista videograbada se constituye en una herramienta de justicia terapéutica, al permitir que se cumplan los distintos fines del procedimiento y de los actores del sistema, pues reconoce al niño, niña o adolescente como un sujeto de derechos y no un objeto del proceso. Representa un esfuerzo institucional y clara expresión de política pública para proteger los derechos de los niños, niñas y adolescentes, al reconocer que son personas dignas con derecho a ser oídos, así como su derecho a la protección de la integridad sicológica. En este sentido, Droppelmann (2003: 4) nos señala que «las intervenciones del juez pueden impulsar este proceso a través de la empatía, es decir, la intención de comprender la perspectiva del otro, evitando críticas y confrontaciones».

Es cierto que este cambio representa un desafío para jueces, fiscales y defensores, quienes deben adaptar sus estrategias de litigación en este nuevo contexto, pero hay que decir que es preferible al escenario anterior, en donde básicamente se negaba la condición de niñez, su especial circunstancia de desarrollo sicoemocional y se lo trataba como un objeto de pericias, equivalente a cualquier cosa que es susceptible de reiteradas pruebas. «No me preguntes más» era el lema de la campaña que en su tiempo impulsó la fundación Amparo y Justicia, sostenido no en meras apreciaciones personales, sino en la evidencia científica recabada en diversos seminarios internacionales y encuentros con expertos de países donde ya se han implementado experiencias similares.

\section{Conclusiones}

El derecho del niño a ser oído es, probablemente, la forma más directa y concreta de reconocer su calidad de sujeto de derechos en un proceso. Pero no basta con oír, con escuchar; es necesario establecer que este derecho debe ser en su beneficio, y nunca puede alterar o perjudicar su derecho a la salud mental.

11. «¿Qué es la justicia terapéutica», Asociación de Justicia Terapéutica, disponible en achtj.cl/ justicia-terapeutica/. 
No es coherente con un debido proceso que la víctima, en este caso un niño, niña o adolescente, sea tratada como objeto de pericia, o emplear las mismas técnicas de interrogatorio y contrainterrogatorio que se usan con adultos. Son seres humanos distintos de los adultos, tiene percepciones distintas, opiniones, sentimientos y procesos de desarrollo que deben ser considerados. El debido proceso, o un proceso «racional y justo», no se reduce a la igualdad de armas, derecho a la acción, juez imparcial y defensa en juicio: es importante considerar también las especiales características de los sujetos que en ello participan, para impedir vulneraciones a otros derechos fundamentales.

La entrevista videograbada es un avance en este sentido, y de hecho marca un giro copernicano en el abordaje de los niños, niñas y adolescentes en su participación en el proceso penal. No era suficiente plasmar en un artículo que pueden ser interrogados mediante el juez presidente del tribunal, o que incluso se puede adelantar su declaración. Era necesario establecer cómo preguntar, quién puede preguntar, en qué oportunidad, en qué espacio y cuántas veces.

La pandemia que afecta al país ha retrasado su implementación a nivel nacional y dificulta el proceso, pues los medios tecnológicos actuales no son idóneos para cumplir lo prescrito en la ley. Pero desde ya asienta un avance sin retroceso posible: no basta decir que los niños tienen derechos. Esos derechos deben hacerse carne, deben poder tocarse, verse, sentirse, y el niño, la niña y el adolescente deben poder experimentar esa diferencia de trato favorable, que los protege y resguarda, deben tener esa tranquilidad, para que así podamos decir que también ahora son sujetos de derechos.

Todas las críticas formuladas al sistema fueron superadas, y solo queda evaluar su implementación. Asimismo, queda pendiente la evaluación de los entrevistadores acreditados, y la detección de los problemas de implementación que se susciten. Resta entonces poner en marcha este sistema para otorgar por fin un reconocimiento, y un espacio adecuado, a los niños, niñas y adolescentes víctimas y testigos de estos delitos tan graves, y que así el sistema judicial no se convierta en otro espacio de vulneraciones, sino de protección, respeto y consideración.

\section{Referencias}

Amparo y Justicia (2020). Entrevista videograbada a niños, niñas y adolescentes víctimas de delitos sexuales, fundamentos y orientaciones técnicas para su implementación. Segunda edición actualizada. Santiago: Fundación Amparo y Justicia, Ediciones UC.

Baytelman, Andrés y Mauricio Duce (2004). Manual de litigación en juicios orales. Santiago: Centro de Estudios de Justicia de las Américas. 
Cortés, Flavio (director) (2009). «Percepción de los procesos de investigación y judicialización en los casos de agresiones sexuales infantiles en la regiones Metropolitana, de Valparaíso y del Biobío». Estudio MIDE UC. Santiago: Pontificia Universidad Católica de Chile. Disponible en bit.ly/3d7LIKc.

Droppelmann, Carla (2009). «Justicia terapéutica: El juez como agente de cambio». Santiago: Paz Ciudadana. Disponible en bit.ly/3dgzkcr.

DucE, Mauricio (2014). «Algunas reflexiones sobre los derechos de las víctimas en el proceso penal chileno». Política Criminal, 9 (18): 739-754. Disponible en bit. ly/2Uxtv2d.

García MÉndez, Emilio (2004). «Entre el autoritarismo y la banalidad: infancia y derechos en América Latina». Justicia y Derechos del Niño, 6: 9-26.

Henríquez Galindo, Sergio Andrés (2017). «El Consejo Técnico de los Tribunales de Familia de Chile: Regulación, límites y proyección». Revista de Derecho (Escuela de Posgrado), 9: 134-170. Disponible en bit.ly/3xSPWgN.

Malloy, Lindsay C., David J. La Rooy, Michael E. Lamb y Carmit Katz (2010). «Developmentally sensitive interviewing for legal purposes». En Michael E. Lamb, David J. La Rooy, Lindsay C. Malloy y Carmit Katz (editores), Children's testimony: A handbook of psychological research and forensic practice (pp. 1-13). Wilye. DOI: 10.1002/9781119998495.ch1.

López Hernández, María Edith (2018). Buenas prácticas en investigación y persecución penal con enfoque de género a nivel iberoamericano. Ciudad de Guatemala: Eurosocial, Cyan. Disponible en: bit.ly/3yFzyBb.

Lyon, Thomas D. (2014). «Interviewing children». Annual Review of Law and Social Science, 10: 73-89. DOI: 10.1146/annurev-lawsocsci-110413-030913.

Reinhardt, Paul H. (2009). «El uso de asistencias testimoniales en tribunales adaptados a los niños: La experiencia canadiense». En Acceso a la justicia de niños/ as víctimas: Protección de los derechos de niños, niñas y adolescentes víctimas o testigos de delitos o violencia (pp. 83-119). ADC, Jufejus, Unicef. Disponible en bit. ly/3hVmOAx.

Torres Hermosilla, Javiera Paz (2019). «La introducción de la entrevista investigativa videograbada de niños, niñas y adolescentes, víctimas de delitos sexuales en el juicio oral: Pugna entre el derecho a defensa del imputado y el interés superior del niño». Memoria para optar al grado de licenciada en Ciencias Jurídicas y Sociales, Facultad de Derecho de la Universidad de Chile. Disponible en bit.ly/34nftBK.

Varsi Rospigliosi, Enrique (2017). "Clasificación del sujeto de derecho frente al avance de la genómica y la procreática». Acta Bioethica, 23 (2): 213-225. DOI: 10.4067/S1726-569X2017000200213. 


\section{Sobre el autor}

Sergio Andrés Henríquez Galindo es abogado egresado de la Universidad de Chile. Magíster en Derechos de la Infancia, la Adolescencia y la Familia de la Universidad Diego Portales, Chile. Magíster en Derecho Procesal de la Universidad Nacional de Rosario, Argentina. Miembro de la Asociación Chilena de Justicia Terapéutica, de la Asociación Nacional de Magistrados y Magistradas y del Instituto Panamericano de Derecho Procesal, capítulo Chile. Su correo electrónico es sergiohenriquez@ gmail.com. (D) https://orcid.org/0000-0002-8182-4735. 
La Revista de Estudios de la Justicia es publicada, desde 2002, dos veces al año por el Centro de Estudios de la Justicia de la Facultad de Derecho de la Universidad de Chile. Su propósito es contribuir a enriquecer el debate jurídico en el plano teórico y empírico, poniendo a disposición de la comunidad científica el trabajo desarrollado tanto por los académicos de nuestra Facultad como de otras casas de estudio nacionales y extranjeras.

\author{
DIRECTOR \\ Álvaro Castro \\ (acastro@derecho.uchile.cl) \\ SITIO WEB \\ rej.uchile.cl \\ CORREO ELECTRÓNICO \\ cej@derecho.uchile.cl \\ LICENCIA DE ESTE ARTÍCULO \\ Creative Commons Atribución Compartir Igual 4.o Internacional
}

La edición de textos, el diseño editorial y la conversión a formatos electrónicos de este artículo estuvieron a cargo de Tipográfica

(www.tipografica.io) 